\title{
Hierarchical power control of multiterminal HVDC grids
}

\author{
Agustí Egea-Alvarez $^{\mathrm{a}}$, Jef Beerten ${ }^{\mathrm{c}}$, Dirk Van Hertem ${ }^{\mathrm{c}}$, Oriol Gomis-Bellmunt ${ }^{\mathrm{a}, \mathrm{b}}$ \\ ${ }^{a}$ Centre d'Innovaci Tecnolgica en Convertidors Esttics i Accionaments (CITCEA-UPC), Departament \\ d'Enginyeria Elèctrica, Universitat Politàcnica de Catalunya. ETS d'Enginyeria Industrial de \\ Barcelona, Av. Diagonal, 647, Pl. 2. 08028 Barcelona, Spain Tel: +34 934016727, Fax: +34 \\ 934017433, e-mail: agusti.egea@citcea.upc.edu. \\ ${ }^{b}$ Catalonia Institute for Energy Research (IREC), Electrical Engineering Area, Jardins de Dones de \\ Negre 1, 08963 Sant Adri de Bess, (Barcelona), Spain. \\ ${ }^{c}$ Electrical engineering department, division ELECTA, of the University of Leuven, Kasteelpark \\ Arenberg 10, bus 24453001 Leuven-Heverlee (Belgium)
}

\begin{abstract}
This article introduces a hierarchical power control structure for Multi-terminal High Voltage Direct Current (MT-HVDC) systems. The presented hierarchy is similar to the control structure used in classical AC transmission systems and is divided in primary, secondary and tertiary control actions. The voltage control in the MT-HVDC scheme acts in a way similar to the primary control action of generators in AC systems, while the secondary control action is performed by an outer power control loop. The design of the individual controllers and the interaction between these control loops is discussed in detail. Furthermore, the operational characteristics are described and the main operating points are identified. Scenarios including a power reference change and a grid side converter disconnection have been simulated in order to test and verify the proposed method. The main contribution of the paper is the development of a control methodology, providing a separation of the different control actions in different time domains, similar to what is already in use (and therefore known) within traditional power systems.
\end{abstract}

Keywords: MT-HVDC system, droop control, power control, hierarchical structure, offshore wind farm.

\section{Introduction}

The energy policy in Europe is based on three main pillars: sustainability, compet2 itiveness and security of supply. This has led to the creation of a liberalized internal energy market, where a significant part of the energy supply is provided by renewable energy sources, mostly from solar and wind. Where the initial renewable power plants were quite small, their size has increased significantly over the years. The latest trend is the move towards offshore wind generation. In 2012 in Europe, 1166 MW of offshore wind power have been installed, representing about $11 \%$ of the new wind power installed 
in Europe [1]. The increase in renewable generation requires a fundamental upgrade of the energy infrastructure. Firstly to connect all the (new) renewable generation to the existing grid, secondly to reinforce the existing grid to accommodate the new generation and thirdly to compensate for the capacity factor which is much lower for renewables.

Nowadays, the dominant transmission technology is still classical AC transmission, but HVDC (High Voltage Direct Current) transmission is gaining much attention in the power sector. HVDC offers the advantage of straightforward long underground connections at high power ratings. As such, this technology is now used for onshore connections where using overhead lines is difficult, for instance due to permitting issues [2], as well as for offshore wind farm transmission [3]. The choice between different transmissions technologies is a technical-economical problem $[4,5]$. As such, a considerable part of the new transmission system investments is now done using HVDC. ENTSO-E predicts that in the next 10 years $1 / 5^{\text {th }}$ of the required updates will be done in the form of HVDC[6]. This represents about $12000 \mathrm{~km}$ of new HVDC transmission lines in Europe.

Most existing HVDC lines are point-to-point connections. A step further is the creation of HVDC grids [7, 8]. Several projects and initiatives focus on the development of a Multi-terminal HVDC (MTDC) grid. Examples are the Supergrid or the DESERTEC projects $[9,10]$. The main concept of both projects is to create a pan-European system to integrate a large amount of renewable energy resources to the AC grid.

These MT-HVDC grids are made possible by the relatively new Voltage Source Converter (VSC) HVDC technology. Compared to Line Commuted Converter (LCC) HVDC, VSC HVDC converters use a common DC bus voltage allowing straightforward parallel connections, they permit independent control of active and reactive power [11]. Furthermore, VSC technology offers blackstart capabilities and comes at a reduced footprint $[12]$.

There are several challenges to be addressed in the development of the MT-HVDC grids. Protection and control of the MT-HVDC grid and the interaction with the AC system are some of the main issues to be solved and the reliable operation of DC grids requires DC breakers [7]. Although such breakers are not yet commercially available, prototypes have been presented [13].

Different ways to control the DC voltage in a DC grid have been described in literature, and there is a general tendency to favour droop based control methods (An overview of the different methods is given in[14]). From the point of view of power flow control, the droop control as such does not allow to fix the power that is injected by a converter due to constant variations in operation points. If the droop control action is in effect, for example, after a converter outage, the powers change according to the droop characteristics and do 
no longer reflect the pre-fault values. For this reason, outer control loops are required to control the droop setpoints and thereby the converter powers. Some authors propose a centralized controller which sets optimized voltage references to the local controllers [15] using a fast communications system. Others propose to design the power controller based on droop regarding the power flow control in the steady state $[16,17]$.

In [18] a hierarchical control scheme was presented. The present paper describes the proposed scheme in greater detail. The objective of the proposed control structure is to allow power flow control in the DC network while ensuring that the terminal voltages are maintained stable within appropriate limits. This is achieved by designing a hierarchical control structure where the power flow (high level) controller sets the references for the voltage (low level) control. The proposed structure is comparable to the classical AC control system and allows for an integrated management of the MT-HVDC regarding the DC voltage and the power flow control. The cascaded interaction between controllers, considering slow communications, makes the implementation of the proposed control feasible in a real system. Aspects such as the degraded operation or the power rescheduling after a contingency have been considered. First the DC voltage droop control is discussed. The resemblance with the AC primary control is shown. In the next step, the power control is introduced and discussed and its similarities with the AC secondary control mechanism are shown. Furthermore, the operating points and modes of the MT-HVDC are described. The proposed control structure also allows the introduction of a tertiary control mechanism, which is rather an optimization than a control in itself and therefore not dealt with in detail in this paper. Finally, simulation results for various scenarios show the validity of the proposed method to control the power flows.

\section{Control structure description}

\subsection{Balancing generation and load}

One of the fundamental controls in electric grids manages the balance between generation and load. Put differently, the balance between the injected and withdrawn power in a grid must remain equal. In AC systems, this balance is reflected in the value of the frequency. The power balance is maintained by the frequency control mechanism. This mechanism adjusts the power outputs of the generation (or possibly the load) to assure a constant frequency. Although different implementations exist throughout the world [19], the control reactions can be generally subdivided in three time domains with different specific actions in each $^{1}$ (Fig. 1).

\footnotetext{
${ }^{1}$ Note that fourth control action, time correction, is not discussed here.
} 
The first control action is an automatic reaction of all activated generators after a deviation of the frequency from the nominal frequency. In a multi-zonal system, this results in a change of output power throughout the system. The power deviation is proportional to the frequency deviation (droop control). The primary control is activated in a very short time period (15-30 seconds) and acts to limit the frequency deviation. The set-point for the active power injections in the different generating units during the primary control action remains at the initial value. The primary control actions are available for only a limited time period (e.g. 15 minutes).

The secondary control action restores the original exchanges between different zones, causing the ACE (Area Control Error) to get back to zero. The secondary control action changes the active power set-points in the area with a power deficit or excess to match the original schedule. Due to the change in set-point in the affected zone by the secondary control, the previously committed primary reserves are no longer required, and in fact overcompensate the initial fault. This effect is again automatically cancelled by the primary control action which moves back to the original value in the entire system, thus releasing the previously activated primary reserves. The tertiary control action shifts the power from the secondary reserves, which are available on a short time basis to more long term power generation, and is often manually activated by the system operator as the result of a system optimization.

[Figure 1 about here.]

\subsection{Balancing injections to and from the $D C$ grid}

The power exchange to and from the DC grid have to be balanced in a similar manner as the AC system. Where the AC system power balance is reflected in a constant frequency, the DC voltage perform a similar role in the DC system. The power-frequency control in the AC system is therefore very similar to the power-DC Voltage control scheme. Several control schemes have been proposed in literature [16, 20, 15]. The consensus seems to lead to a droop controlled DC voltage [14, 17, 21], much like the primary control actions which are used in AC systems. This shift complicates the power control in the system, making it not possible to copy the AC control methodology. Contrary to the AC system, which exhibits a significant inertia from the kinetic energy in the rotating machines, the stored energy in the DC system is very limited, with only the charge in the DC capacitors and cables. This makes that the voltages in the DC system change much faster than in the AC case (frequency power imbalance). The response of the controllers should therefore be equally fast. The time constant for the primary control loop is in the order of a ten's of milliseconds and is thus dictated by the DC grid characteristics. For the 
secondary control this can be relaxed as the primary response already aims at stabilizing the system voltage. Consequentially, this control can be in the order of seconds or tens of seconds. Traditional tertiary controllers are off-line algorithms that react between 20 minutes and 1 hour. Similarly as with the AC system, when a fault occurs (e.g. when a converter station is disconnected), the control of the DC voltage causes the different converter systems to adjust their power injections immediately, distributing the deficit according to the droop settings. As the voltage control at the DC side directly influences the power exchanges, there is a need to adjust the power injection set-points to meet the scheduled exchanges, especially if multiple zones or synchronous zones are connected to the DC grid. This requirement is very much in line with the secondary and tertiary control which is used in the AC system.

The proposed control scheme introduces an upper level controller to the HVDC voltage control which can be compared to classical AC grid controls, consisting out of a primary, secondary and tertiary control [22]. This structure permits to create an easy interaction between power dispatch and the lower controllers using a methodology which is well accepted and known in the power sector.

[Figure 2 about here.]

A voltage controller is implemented in each VSC power converter and acts as a primary controller. Secondary control, or power control, is implemented to correct the exchanges so that the pre-disturbance conditions are restored. The practical implementation is a change of the voltage set-points in the affected VSC controllers. The new set-points are provided by a system-wide DC redispatch. Finally a tertiary control mechanism can be used to calculate the power reference according to a more optimal operation of a power system considering market, losses, security, current and voltage restrictions, environmental constrains, among others. Tertiary control can be based on OPF (Optimal Power Flow) algorithms considering AC and DC grids. Fig. 2 shows a comparison between the AC and the proposed DC control approach.

\section{Control implementation}

\subsection{Current loop}

The current loop is the basic control loop for a VSC. This loop permits to inject the desired active and reactive current to the electrical grid. Fig. 3 shows the implementation of the current loop and the interaction with the primary controller based on vector control[11]. The active power reference is given by the primary control and the reactive power reference can be obtained according to grid code requirements. 


\section{3.2. Primary control}

The primary control or voltage control is the controller in charge of the DC voltage. The most common voltage control is the so-called droop. It is a proportional control law that controls the DC current according to the DC voltage. The droop implementation for a rectifier and an inverter converter are defined respectively as

$$
\begin{aligned}
& I_{D C-\text { rec }}^{*}=k_{\text {droop }}\left(E_{\text {rec }}^{*}-E_{D C}\right), \\
& I_{D C-\text { inv }}^{*}=k_{\text {droop }}\left(E_{D C}-E_{\text {inv }}^{*}\right),
\end{aligned}
$$

with $I_{D C}^{*}$ the reference current, $k_{\text {droop }}$ the gain of the droop controller, $E_{i n v}^{*}$ the voltage offset for the inverter units and $E_{r e c}^{*}$ the voltage offset of the rectifier units.

Fig. 4 shows the operation characteristic of the droop controller under inverter operation (a), and rectifier operation (b). Once the power converter current limit is reached the current is saturated and no more power is injected to the grid. The droop gain $k_{d r o o p}$ is calculated following the methodology presented in [21].

Wind farms connected to the DC grid are set to inject all the generated power in the DC grid. When an electrical fault occurs, it may result in the saturation of the power converter current limit and, consquenlly, not all the power can be injected in the grid. As such, the DC voltage will rise quickly. In order not to exceed the maximum permitted voltage, a wind farm power reduction method is needed. The power reduction method uses a droop characteristic that reduces the injected power. This power reduction can be physically implemented using a DC chopper or a wind turbine reference change. Using the last option, the power reduction control law is defined as

$$
P_{\text {wind }}^{r e d}=P_{\text {wind }}\left(1-k_{r}\left(E_{D C}-E_{\text {min }}^{W F}\right)\right),
$$

where $P_{\text {wind }}$ is the wind farm power, $P_{\text {wind }}^{r e d}$ is the reduced wind farm power, $E_{D C}$ is the DC voltage and $k_{r}$ can be chosen as

$$
k_{r}=\frac{1}{E_{\max }^{W F}-E_{\text {min }}^{W F}},
$$

where $E_{\max }^{W F}$ and $E_{\min }^{W F}$ are the upper and the lower thresholds of the DC voltage in terminals of the wind farm power converter.

[Figure 4 about here.] 


\subsection{Secondary control}

The secondary control or power control can be described as a system that allows to achieve the power setpoints provided by a tertiary control. Furthermore, the secondary control corrects the power references after a contingency. In steady state, the main objectives of the secondary control are to ensure the power references and the power exchanges between the areas. A conceptual scheme of the proposed system can be seen in Fig. 5.

[Figure 5 about here.]

The secondary controller is the link between the tertiary and the primary control. The power controller is divided in two parts. The first part is located in the power converter and aims to achieve the given power references modifying the droop offset. This comes down to changing the intersection with the voltage axis $E^{*}$ in Fig. 4. The second part is located remotely and performs the calculations that permit to calculate new power references in case of a change of the operational point.

\subsubsection{Local control structure}

The local power control is based on a PI controller that achieves the desired power references without steady state error. The power controller regulates the power through the power converter by modifying the reference of the droop controller $E^{*}$. The output of the power controllers are saturated in order not to exceed converter voltage and current.

The power controller can be defined as $E^{*} /\left(P^{*}-P\right)=K_{p}+K_{i} / s$, where $K_{p}$ is the proportional gain of the controller and $K_{i}$ is the integral gain of the controller. The controller is tuned to obtain a time response in the order of seconds.

\subsubsection{Central DC redispatch}

The central DC redispatch recalculates the power references in case of a contingency (e.g. converter outage) or a deviation of the power references (e.g. change in power injection from an offshore wind farm). The central DC redispatch consists of a centralized controller that receives status information from the power converters, as well as the power references given by the tertiary control. The outputs are the sent new power references.

In normal operation, the sent power references match those given by the tertiary control and no reference modifications are required. In case a power converter disconnection, the given references cannot be maintained. In this case, the central DC redispatch tries to restore the power exchange between areas. This means that if one area is supplied by two power converters and one power converter is disconnected, the control objective is to restore the scheduled power flow to or from this area. This is done by having the second 
converter taking over the power from the converter facing an outage (as long as internal control limits are not hit). This is shown in Fig. 6 .

The operation of the mentioned central calculation structure requires a communication system between the local power converter and the central calculation itself. Compared to other systems $[15,16]$, the described system does not require a critical communication system due to the intrinsic safe operation characteristic of the droop-based primary control method.

[Figure 6 about here.]

\subsubsection{Operating points}

During normal operation, the power controllers modify the offset of the droop controller, i.e. the intersection with the voltage axis $E^{*}$, to achieve the desired power flow through the power converter. In normal operation the voltage can vary between a minimum and maximum value, as shown in Fig. 7.

When the system operates in a degraded state, e.g. an $\mathrm{AC}$ voltage sag or a power converter disconnection, the power balancing in the system cannot be accomplished. In this case, the operation of the system moves to a fixed droop offset. The droop offset is limited in the upper region by the $E_{\max -i}$ and $E_{\max -r}$ and the lower region by the $E_{m i n-i}$ and $E_{m i n-r}$. The subscript $i$ refers to inverter and $r$ to rectifier. The appropriate selection of the described limits permits to operate the system under fault operation without exceeding the voltage limits while operating the system as an usual MT-HVDC droop controlled system.

[Figure 7 about here.]

\subsection{Tertiary control}

The tertiary control is the upper control level and schedules the injections according to a given objective function taking into account economical and technical aspects, as well as their constraints. The tertiary control can be based on OPF algorithms. The required tertiary control used in the presented scheme can be a classical tertiary control based on a power flow considering DC transmission systems [22]. Resistive losses are considered in this stage of the system and are included in the OPF calculation.

\section{System modelling and controller design}

In this section, both a generic MT-HVDC configuration model and wind farm model are presented. In order to illustrate the modelling procedure, a four terminal scheme 
model (Fig.11) is shown. It is assumed that the Grid Side Converter (GSCs) are connected to strong $\mathrm{AC}$ connection points to simplify the study.

\subsection{DC grid modelling}

Power converters connected to the MT-HVDC grid are modelled as equivalent DC sources based on the average model presented in [17]. Specifically, the Wind Farm Converters (WFCs) are modelled as a linearised power source as they are assumed to inject the generated power to the MT-HVDC system. Then, the generic WFC model including the DC converter capacitor is

$$
\Delta \dot{E}_{x}=-\frac{1}{C E_{x 0}^{2}} \Delta E_{x}-\frac{1}{C} \Delta I_{x}+\frac{1}{C E_{x 0}} \Delta P_{x}
$$

where $\Delta I_{x}$ is the transmission line current, $\Delta P_{x}$ is the injected power and $\Delta E_{x}$ is the voltage at the converter terminals. Terms with a 0 subscript $\left(E_{x 0}, P_{x 0}\right)$ refer to the value at the linearisation point.

The GSC is modelled, as it is aforementioned, as a linear DC current source as

$$
\Delta \dot{E}_{x}=-\frac{1}{C} \Delta I_{i n x}+\frac{1}{C} \Delta I_{x}
$$

where $\Delta I_{i n x}$ is the converter current. Regarding the DC grid, the transmission cables are modelled as $\pi$ equivalent cables. Then, the cable generic model, assuming that the converter and line capacitors have been combined, is

$$
\Delta \dot{I}_{x}=-\frac{R_{x}}{L_{x}} \Delta I_{x}+\frac{1}{L_{x}} \Delta E_{x}^{+}-\frac{1}{L_{x}} \Delta E_{x}^{-}
$$

where $L_{x}$ and $R_{x}$ are the line resistance and inductance. The subscript ${ }^{+}$and ${ }^{-}$ indicate the node with higher and lower voltage.

\subsubsection{Four terminal MT-HVDC}

In this section, the four terminal grid model shown in Fig. 11 is obtained employing equations 5,6 and 7. Equations 8 and 9 show the system state space representation

$$
\begin{aligned}
\Delta \dot{x}_{d c} & =A_{d c} \Delta x_{d c}+B_{d c} \Delta u_{d c} \\
\Delta y_{d c} & =C_{d c} \Delta x_{d c}+D_{d c} \Delta u_{d c}
\end{aligned}
$$


${ }_{257}$ where the state $A_{d c}$, input $B_{d c}$ and output $C_{d c}$ and $D_{d c}$ matrices are

$$
A_{d c}=\left(\begin{array}{ccccccc}
\frac{-P_{10}}{C E_{10}^{2}} & 0 & 0 & 0 & \frac{-1}{C} & \frac{-1}{C} & 0 \\
0 & 0 & 0 & 0 & \frac{1}{C} & 0 & 0 \\
0 & 0 & 0 & 0 & 0 & \frac{1}{C} & \frac{-1}{C} \\
0 & 0 & 0 & 0 & 0 & 0 & \frac{1}{C} \\
\frac{1}{L_{1}} & \frac{-1}{L_{1}} & 0 & 0 & \frac{-R_{1}}{L_{1}} & 0 & 0 \\
\frac{1}{L_{2}} & 0 & \frac{-1}{L_{2}} & 0 & 0 & \frac{-R_{2}}{L_{2}} & 0 \\
0 & 0 & \frac{1}{L_{3}} & \frac{-1}{L_{3}} & 0 & 0 & \frac{-R_{3}}{L_{3}}
\end{array}\right)
$$

$$
\begin{aligned}
& C_{d c}=\left(\begin{array}{ccccccc}
1 & 0 & 0 & 0 & 0 & 0 & 0 \\
0 & 1 & 0 & 0 & 0 & 0 & 0 \\
0 & 0 & 1 & 0 & 0 & 0 & 0 \\
0 & 0 & 0 & 1 & 0 & 0 & 0 \\
0 & I_{i n 20} & 0 & 0 & 0 & 0 & 0 \\
0 & 0 & I_{i n 30} & 0 & 0 & 0 & 0 \\
0 & 0 & 0 & I_{i n 40} & 0 & 0 & 0
\end{array}\right) \\
& D_{d c}=\left(\begin{array}{cccc}
0 & 0 & 0 & 0 \\
0 & 0 & 0 & 0 \\
0 & 0 & 0 & 0 \\
0 & 0 & 0 & 0 \\
0 & E_{20} & 0 & 0 \\
0 & 0 & E_{30} & 0 \\
0 & 0 & 0 & E_{40}
\end{array}\right)
\end{aligned}
$$

259 and the state, input and output vector are

$$
\begin{aligned}
& x_{d c}=\left[\Delta E_{1} \Delta E_{2} \Delta E_{3} \Delta E_{4} \Delta I_{1} \Delta I_{2} \Delta I_{3}\right]^{T}
\end{aligned}
$$

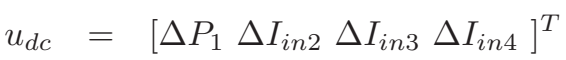

$$
\begin{aligned}
& y_{d c}=\left[\Delta E_{1} \Delta E_{2} \Delta E_{3} \Delta E_{4} \Delta P_{2} \Delta P_{3} \Delta P_{4}\right]^{T}
\end{aligned}
$$




\subsection{Wind farm modelling}

The wind farm has been modelled as a simplified power aggregated model based on [23] and shown in Fig. 8. The main objective of the proposed model is to reflect the power variation due to the wind speed variation. For this reason, the wind farm consist in a table that varies the injected power as a function of the wind speed according to a wind turbine power/wind speed characteristic [23]. After, this power is filtered by the rotor inertia dynamics $\left(G_{m e c}(s)=1 /(J s+1)\right)$, where $J$ is the rotor time constant inertia and the simplified electrical dynamics $\left(G_{\text {ele }}(s)=1 /(\tau s+1)\right)$, where $\tau$ is the electrical time constant. Furthermore, the power reduction described in subsection 3.2 is also implemented.

[Figure 8 about here.]

\subsection{Control Design}

The converter local control structure presented in 3.3 is a cascaded based control topology where the inner loops are designed to be faster than the outer loops, in order to avoid non-desired interactions between controllers. The interaction between the local converter control structure and the DC grid linearised model is depicted in Fig. 9.

[Figure 9 about here.]

The inner current loop is tuned using the Internal Model Control (IMC) method [24], ensuring a first order time response $\alpha$ on the $\mathrm{AC}$ side. Regarding the $\mathrm{DC}$ side, it is assumed to present the same time response as the inner current control. Primary or droop control is tuned in order to avoid DC grid resonances, to limit the control voltage errors and not to interact with the inner current controller [17]. Secondary control is designed based on the transfer function relating the primary voltage reference $\left(E_{x}^{*}\right)$ and the converter exchanged power $\left(P_{x}\right)$

$$
P_{x}=\frac{-E_{x 0} C k_{d r o o p} s+I_{\text {inx } 0} k_{d r o o p}}{C \alpha s^{2}+C s+k_{d r o o p}} E_{x}^{*}+\frac{I_{i n x 0} \alpha s+E_{x 0} k_{d r o o p}+I_{i n x 0}}{C \alpha s^{2}+C s+k_{d r o o p}} I_{x}
$$

where $I_{i n x 0}$ is the linearised converter injected current at the linearisation point. This transfer function has two different inputs, the primary voltage input $E_{x}^{*}$, which is the output of the secondary control and the current flowing through the DC transmission line $I_{x}$, which is considered as a system disturbance. The PI controller is tuned using the disturbance rejection IMC methodology described in [25], considering the following gains

$$
\begin{array}{r}
K_{p}=\frac{C}{\left(\lambda I_{i n x 0}+C E_{x 0}\right) k_{d r o o p}} \\
K_{i}=\frac{K_{p} k_{d r o o p}}{C}
\end{array}
$$


where $\lambda$ is the secondary controller desired time constant. This constant is selected to have a very smooth system transient response. For this reason, it should be almost 100 times slower than the primary control time constant, setting the overall system response in the order of seconds. Plotting the secondary control close loop bode representation (Fig. 10) relating variables $\frac{P_{x}}{P_{x}^{*}}$, it can be observed that the system is able to perfectly track constant power references. It also can be seen that a damped peak related to primary control appears at higher frequencies, which is not affecting the reference tracking due to its relatively reduced gain. This plot reveals also that the closed loop time response of the system is in the order of seconds, according to bode the crossover frequency, as desired.

[Figure 10 about here.]

In addition, a Low Pass Filter (LPF) has been added to the measures in order to filter the measurement noise. Due to the fast filter dynamic response, it is not considered during the secondary control design phase.

\section{Simulation}

Scenarios have been simulated with Matlab-Simulink in order to test and verify the proposed control scheme. The first simulated scenario is a change in the power reference and the second scenario is a grid side converter disconnection.

The analysed system is the four terminal system, where the dynamic equations have been presented in 4 . One power converter is connected to a wind farm (WFC1). Another power converter is connected to an AC grid (GSC3) and the two other power converter are connected to a second AC area (GSC1 and GSC2), considering an electrical distance between them in the grid side, represented as an AC line. In the studied case, the AC grids are modelled as Thévenin equivalent nodes. A sketch of the system can be seen in Fig. 11. The parameters used in the simulations can be seen in Table 1.

[Figure 11 about here.]

[Table 1 about here.]

From the operation point of view, GSC1 and GSC2 are connected to the same grid working as an unique area. Power converters and the secondary control are communicated each 20s. In the plotted results, the communication instant is indicated with a circle com.

This time can be lower but has been selected at a higher value in order to demonstrate the viability of the system operation in unfavourable scenarios. In the following example, 
the DC redispatch changes the GSC3 original active power set point $\left(P_{3}^{t e r}\right)$ sent from the tertiary control $\left(P_{3}^{\text {ter }}\right)$ in order to assume the power variation due to the wind variability.

\subsection{Change of reference}

In the first scenario, a power reference change is simulated. At time instant $\mathrm{t}=120 \mathrm{~s}$, a new power reference is sent to two grid side converters. The power changes are described in the Table 2. Figs. 13-12 show the voltage and the power. The actual values of the grid connected power converters are plotted in solid line and reference values in dashed line.

[Table 2 about here.]

In the initial time instant $\mathrm{t}=0 \mathrm{~s}$, the system follows the references shown Table 2 . The real power is equal to the reference power and an equilibrium voltage points are reached. At time instant $\mathrm{t}=120 \mathrm{~s}$, new power references are sent to the GSC1 (inverter) and GSC3 (rectifier). As can be seen in Fig. 12 the power transmitted over the DC grid increases by 40 MW. The dynamics of the system show the typical first order response with a time constant of $1.2 \mathrm{~s}$ which has been chosen as response time for the secondary controller. Depending on the grid requirements, this time constant can be decreased or increased. Also, It can be seen that the remote secondary controller is adjusting the GSC3 reference to accommodate the wind power variations (difference between the reference sent by the tertiary control reference $P_{G S C^{*}}^{t e r}$ and the adjusted reference $P_{G S C^{*}}$ in Fig.12).

[Figure 12 about here.]

Focusing on the power reference change, it is clear from Fig. 13, that the actual voltages before and after the power reference change are relatively similar. The biggest change can be observed in the voltage offsets which are changed as a result of the secondary control action, aiming at achieving the new power references. Furthermore, it can be seen that the GSC3 power reference is adapted by the remote secondary action depending on the power injected by the wind farm. Fig. 14 shows the poles and zeros map of the simulated system. It can be observed that the system is stable because all the poles are in the right hand side plane.

[Figure 13 about here.]

[Figure 14 about here.] 


\subsection{Power Converter Outage}

In the second scenario, the grid side power converter, GSC1, experiences an outage at time instant $\mathrm{t}=10 \mathrm{~s}$. Figs. $15-16$ show the voltage and the power in the MT-HVDC grid.

Before the outage, power converter GSC1 inverts 50 MW, GSC2 inverts 25 MW, GSC3 rectifies $20 \mathrm{MW}$ and the wind farm generates around $50 \mathrm{MW}$. Losses are assumed by the rectifying unit. At time instant $\mathrm{t}=40.5 \mathrm{~s}$, GSC1 is disconnected and the HVDC system power balance is not in equilibrium. Immediately after the fault, the droop action stops the voltage from rising and as a result GSC3 immediately reduces the rectified power and GSC2 increases the inverted power. After that, the secondary controllers start to move the system droop offsets. At time instant t=45 s, GSC2's secondary control is saturated at the maximum limit and the control acts as a droop with a fixed voltage offset.

Between time instants $\mathrm{t}=45 \mathrm{~s}$ and $\mathrm{t}=50 \mathrm{~s}$, the rectifier unit GSC3 increases the droop offset until the power reference is achieved. At instant $\mathrm{t}=55 \mathrm{~s}$, the system is working at a new equilibrium point (constant values of $E^{*}$ ) with a saturated droop characteristic at the inverter side (GSC2) and a non-saturated droop offset at the rectifier side (GSC3). This scenario shows that the system can work without issues or instabilities in this operation point. It can be observed that the reference of the disconnected GSC1 goes to the $E_{\text {min-i }}$ threshold and the wind farm power reduction is not needed. After the time instant $\mathrm{t}=60$ s, new power references considering the outage are sent. These new references match with the previous equilibrium point as far as the power converters were no saturated.

[Figure 15 about here.]

[Figure 16 about here.]

\section{Conclusion}

A new control structure for MT-HVDC grids has been presented. The presented scheme consist of a primary, a secondary and a tertiary control similar to the traditional AC grid controls. The primary control is in charge of the DC voltage stability. The secondary control allows to achieve a given power setpoints, also after a contingency. The tertiary control permits a power scheduling regarding the AC and DC system.

The objective of the proposed control hierarchy is to provide a method that can be implemented in hybrid AC/DC systems with multiple converters connected to different AC and DC systems. The method is HVDC vendor neutral. The methodology is expected to be well accepted by industry as it is similar to existing AC control structures. As such, this method could serve as a base for schemes to be introduced into AC/DC grid codes. 
It is important to note that although the structure is similar to the AC control structures, the time constants differ significantly, specifically those of the inner loops. The operational points of the proposed method, under normal and converter outage have been described. Simulation scenarios, including a power converter disconnection show the validity of the proposed control method for MT-HVDC system.

\section{Acknowledgements}

The work performed by Agustí Egea and Oriol Gomis is supported by the Ministerio de Ciencia e Innovacion under the project ENE2012-33043. The work performed by Jef Beerten is funded by a research grant from the Research Foundation - Flanders (FWO).

\section{References}

[1] EWEA, 2012 european statistics (Febrary 2013).

[2] P. Francos, S. Verdugo, H. Alvarez, S. Guyomarch, J. Loncle, Inelfe europe's first integrated onshore hvdc interconnection, in: IEEE Power and Energy Society General Meeting, 2012.

[3] A. Bodin, Hvdc light a preferable power transmission system for renewable energies, in: Proceedings of the 3rd International Youth Conference on Energetics (IYCE), 2011.

[4] B. Van Eeckhout, D. Van Hertem, M. Reza, K. Srivastava, R. Belmans, Economic comparison of vsc hvdc and hvac as transmission system for a $300 \mathrm{mw}$ offshore wind farm, European Transactions on Electrical Power 20 (5) (2010) 661-671.

[5] H. Ergun, D. Van Hertem, R. Belmans, Transmission system topology optimization for large-scale offshore wind integration, IEEE Transactions on Sustainable Energy 3 (4) (2012) 908-917.

[6] European Network of Transmission System Operators for Electricity (ENTSO-E), Operation handbook, Tech. rep., ENTSO-E (2012).

URL https://www.entsoe.eu/publications/system-operations-reports/ operation-handbook/

[7] D. V. Hertem, M. Ghandhari, Multi-terminal \{VSC $\}\{$ HVDC $\}$ for the european supergrid: Obstacles, Renewable and Sustainable Energy Reviews 14 (9) (2010) 3156 $-3163$. 
[8] N. Ahmed, S. Norrga, H.-P. Nee, A. Haider, D. Van Hertem, L. Zhang, L. Harnefors, Hvdc supergrids with modular multilevel converters; the power transmission backbone of the future, in: 9th International Multi-Conference on Systems, Signals and Devices (SSD), 2012.

[9] S. Gordon, Supergrid to the rescue, Power Engineer 20 (5) (2006) 30 -33.

[10] F. Trieb, C. Schillings, T. Pregger, M. O'Sullivan, Solar electricity imports from the middle east and north africa to europe, Energy Policy 42 (0) (2012) 341 - 353.

[11] A. Egea-Alvarez, A. Junyent-Ferr, O. Gomis-Bellmunt, Active and reactive power control of grid connected distributed generation systems, in: L. Wang (Ed.), Modeling and Control of Sustainable Power Systems, Green Energy and Technology, Springer Berlin Heidelberg, 2012, pp. 47-81.

[12] M. Bahrman, J. Johansson, B. Nilsson, Voltage source converter transmission technologies: the right fit for the application, in: Power Engineering Society General Meeting, 2003, IEEE, Vol. 3, 2003, p. 4 vol. 2666.

[13] J. Haefner, B. Jacobson, Proactive Hybrid HVDC Breakers - A key innovation for reliable HVDC grids, in: Cigre International Symposium. The electrical power system of the future. Integrating supergrids and microgrids. 13-15 September 2011 - Bologna (Italy), 2011.

[14] T. K. Vrana, J. Beerten, R. Belmans, O. B. Fosso, A classification of $\{$ DC $\}$ node voltage control methods for $\{$ HVDC $\}$ grids, Electric Power Systems Research 103 (2013) $137-144$.

[15] M. Aragues, A. Egea, O. Gomis, A. Sumper, Optimum voltage control for loss minimization in HVDC multi-terminal transmission systems for large offshore wind farms, Electric Power Systems Research 89 (2012) 54-63.

[16] L. Xu, L. Yao, DC voltage control and power dispatch of a multi-terminal HVDC system for integrating large offshore wind farms, IET Renewable Power Generation 5 (3) (2011) 223-233.

[17] E. Prieto-Araujo, F. Bianchi, A. Junyent-Ferre, O. Gomis-Bellmunt, Methodology for droop control dynamic analysis of multiterminal vsc-hvdc grids for offshore wind farms, IEEE Transactions on Power Delivery 26 (4) (2011) 2476 -2485. 
[18] A. Egea-Alvarez, J. Beerten, D. V. Hertem, O. Gomis-Bellmunt, Primary and secondary control of multiterminal hvdc grids, in: 10th IET International Confrence on AC and DC Power Transmission, 2012.

[19] Y. G. Rebours, D. S. Kirschen, M. Trotignon, S. Rossignol, A survey of frequency and voltage control ancillary services mdash;part i: Technical features 22 (1) (2007) $350-357$.

[20] W. Lu, B.-T. Ooi, Dc overvoltage control during loss of converter in multiterminal voltage-source converter-based hvdc (m-vsc-hvdc), IEEE Transactions on Power Delivery 18 (3) (2003) 915 - 920.

[21] A. Egea-Alvarez, F. Bianchi, A. Junyent-Ferre, G. Gross, O. Gomis-Bellmunt, Voltage control of multiterminal vsc-hvdc transmission systems for offshore wind power plants: Design and implementation in a scaled platform 60 (6) (2013) 2381-2391.

[22] N. Bengiamin, W. Chan, Multilevel load-frequency control of interconnected power systems, Proceedings of the Institution of Electrical Engineers 125 (6).

[23] L. M. Fernandez, F. Jurado, J. R. Saenz, Aggregated dynamic model for wind farms with doubly fed induction generator wind turbines, Renewable Energy 33 (1) (2008) $129-140$.

[24] J. Morren, S. W. H. D. Haan, Ridethrough of wind turbines with doubly-fed induction generator during a voltage dip, IEEE Transactions on Energy Conversion 20 (2) (2005) 435-441.

[25] B. Wayne, Process control: modemodel, design and simulation, 2012.

[26] European Network of Transmission System Operators for Electricity (ENTSO-E), Operation handbook, Tech. rep., ENTSO-E (2012).

URL https://www.entsoe.eu/publications/system-operations-reports/ operation-handbook/ 


\section{List of Tables}

1 Parameters of the simulated scenario . . . . . . . . . . . . . . . 19

2 Initial and final power for the change of reference scenario . . . . . . . 19

\section{List of Figures}

Different control actions in AC systems and their linkage [26] . . . . . . 20

Comparison between AC and the proposed DC control approach. . . . . . 20

Current loop implementation and droop controller interaction. . . . . . . 21

Droop characteristics depending on the operation of the system. . . . . . 21

General scheme of the proposed control methodology . . . . . . . . . . . . 21

Example of power balancing developed by the reference calculation. . . . 22

7 DC characteristic operation of the power converters for the proposed con-

trol methodology. . . . . . . . . . . . . . . . . . . . . 22

8 Wind farm simplified model . . . . . . . . . . . . . . . . 22

9 Simplified control scheme . . . . . . . . . . . . . . . . 23

10 Close loop transfer function of $\frac{P_{x}}{P_{x}^{*}} \ldots \ldots \ldots \ldots$

11 General scheme of the simulated multiterminal system . . . . . . . . . . . 24

12 Power evolution during a reference change. . . . . . . . . . . . . . . . 24

13 Voltage evolution during a reference change. . . . . . . . . . . . . . 25

14 Poles and zeros map for the simulation scenario 1 . . . . . . . . . . . 25

15 Voltage evolution during a reference change. . . . . . . . . . . . . . . 26

16 Power evolution during a reference change. . . . . . . . . . . . . . 27 


\begin{tabular}{lll} 
Parameter & Value & Units \\
\hline Cable resistance & 0.01 & $\Omega / \mathrm{km}$ \\
Cable inductance & 0.1 & $\mathrm{mH} / \mathrm{km}$ \\
Power converter capacitance (including cable) & 150 & $\mu \mathrm{F}$ \\
Cable 1 length & 100 & $\mathrm{~km}$ \\
Cable 2 length & 20 & $\mathrm{~km}$ \\
Cable 3 length & 90 & $\mathrm{~km}$ \\
Droop controller gain & 0.1 & $\mathrm{~A} / \mathrm{V}$ \\
Maximum droop value for rectifiers $E_{\max -r}$ & 165 & $\mathrm{kV}$ \\
Maximum droop value for inverters $E_{m a x}-i$ & 152.4 & $\mathrm{kV}$ \\
Wind farm lower voltage limit $E_{\text {min }}^{W F}$ & 159 & $\mathrm{kV}$ \\
wind farm higher voltage limit $E_{\text {max }}^{W F}$ & 165 & $\mathrm{kV}$ \\
Proportional gain power controller $k_{p}$ & $2.25 \times 10^{-7}$ & $\mathrm{~V} / \mathrm{W}$ \\
Integral gain power controller $k_{i}$ & $3.5 \times 10^{-5}$ & $\mathrm{~V} /(\mathrm{Ws})$ \\
Low pass filter cut-off frequency & 15000 & $\mathrm{~Hz}$ \\
wind farm inertia time constant & 3 & $\mathrm{~s}$ \\
wind farm electrical time constant & 0.01 & $\mathrm{~S}$ \\
AC short-circuit power & 700 & $\mathrm{MW}$ \\
AC voltage & 220 & $\mathrm{kV}$ \\
AC line resistance $R_{a c}$ & 5 & $\Omega$ \\
AC line inductance $L_{a c}$ & 50.8 & $\mathrm{mH}$ \\
AC line 1 resistance $R_{a c 1}$ & 1.3 & $\Omega$ \\
AC line 1 inductance $L_{a c 1}$ & 10.2 & $\mathrm{mH}$ \\
\hline
\end{tabular}

Table 1: Parameters of the simulated scenario

\begin{tabular}{l|c|c|l} 
Converter & Initial power & Final power & Behaviour \\
\hline GSC2 & $30 \mathrm{MW}$ & $70 \mathrm{MW}$ & Inverter \\
GSC3 & $40 \mathrm{MW}$ & $80 \mathrm{MW}$ & Rectifier
\end{tabular}

Table 2: Initial and final power for the change of reference scenario 


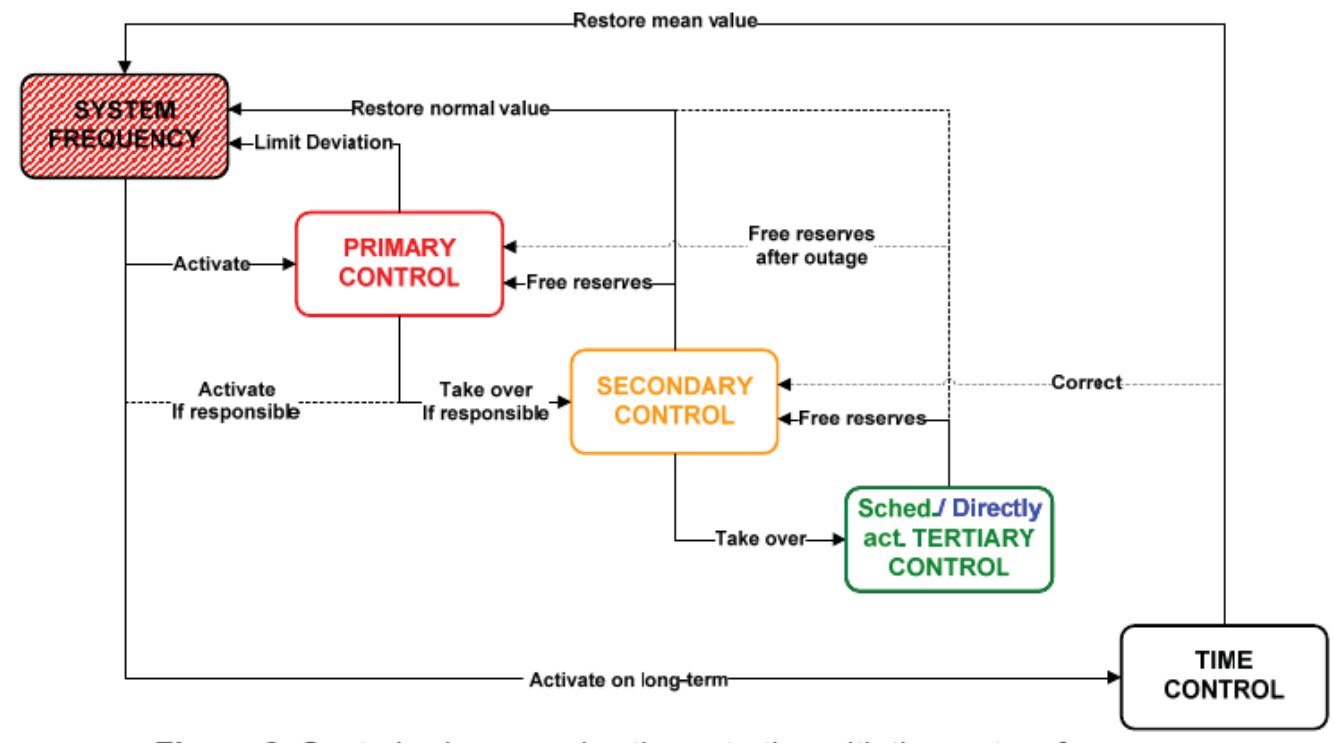

Figure 1: Different control actions in AC systems and their linkage [26].

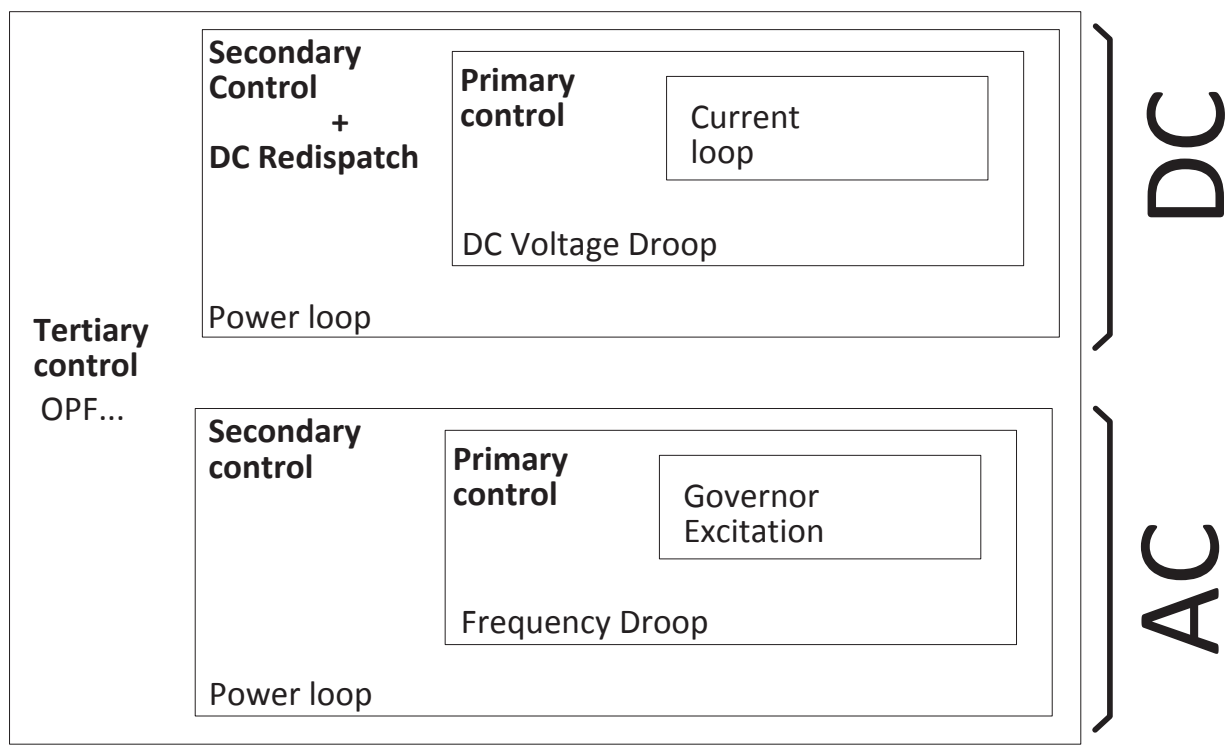

Figure 2: Comparison between AC and the proposed DC control approach. 


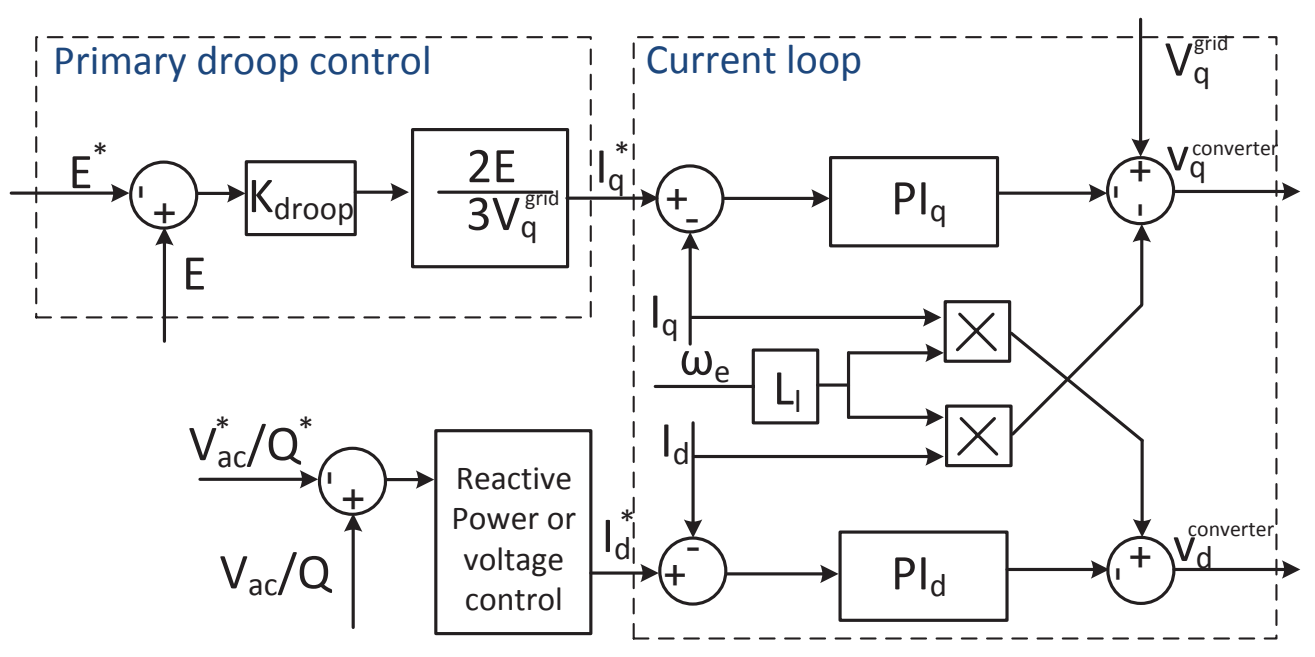

Figure 3: Current loop implementation and droop controller interaction.

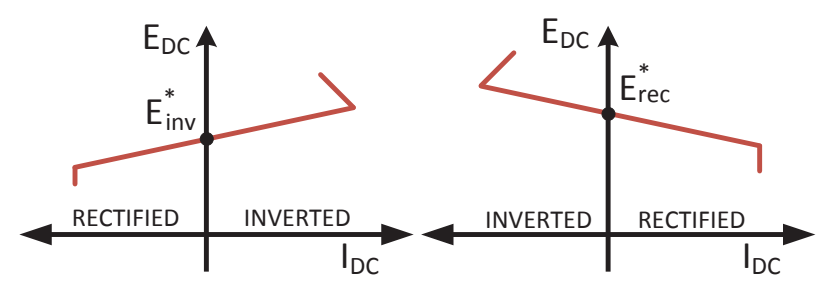

a)

b)

Figure 4: Droop characteristics depending on the operation of the system.

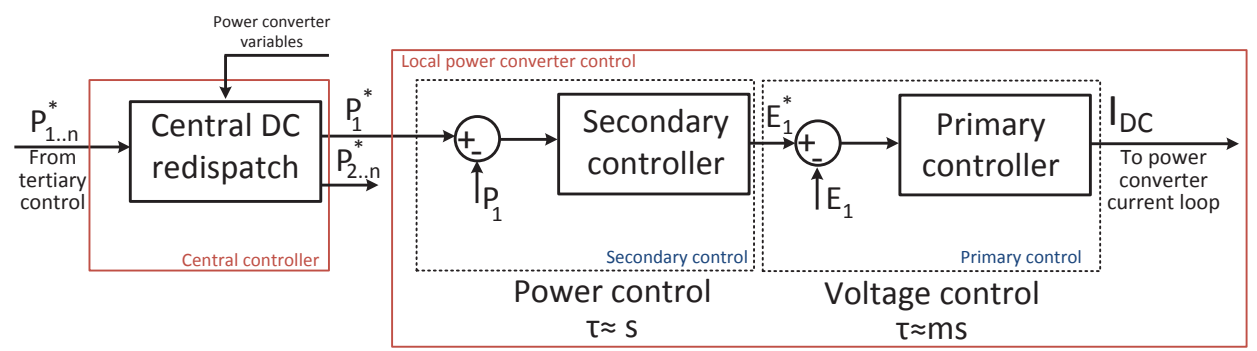

Figure 5: General scheme of the proposed control methodology 


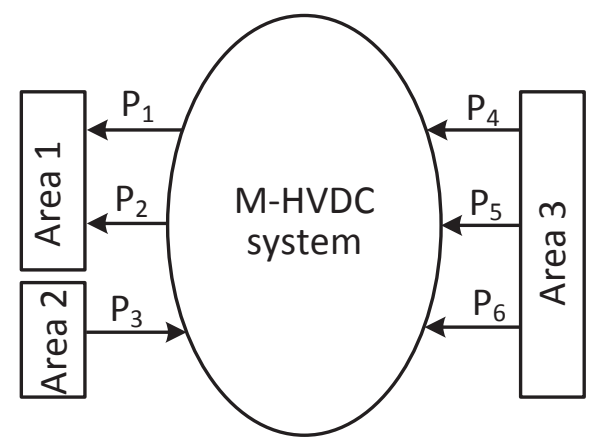

a)

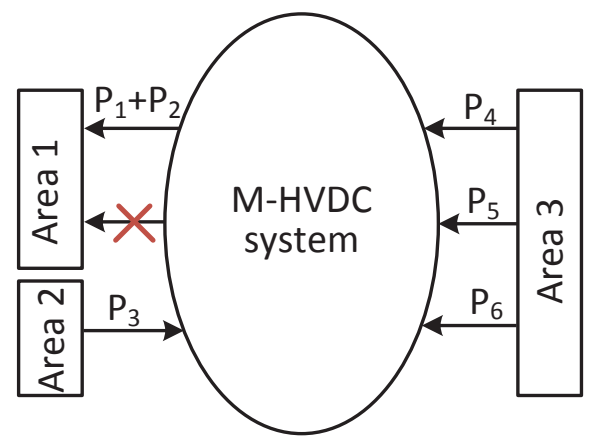

b)

Figure 6: Example of power balancing developed by the reference calculation.
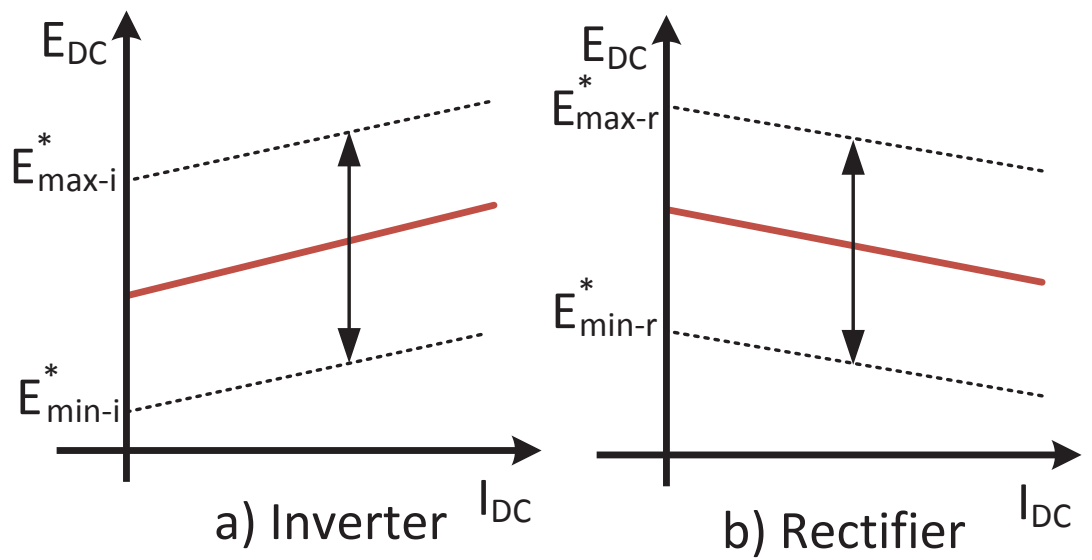

Figure 7: DC characteristic operation of the power converters for the proposed control methodology.

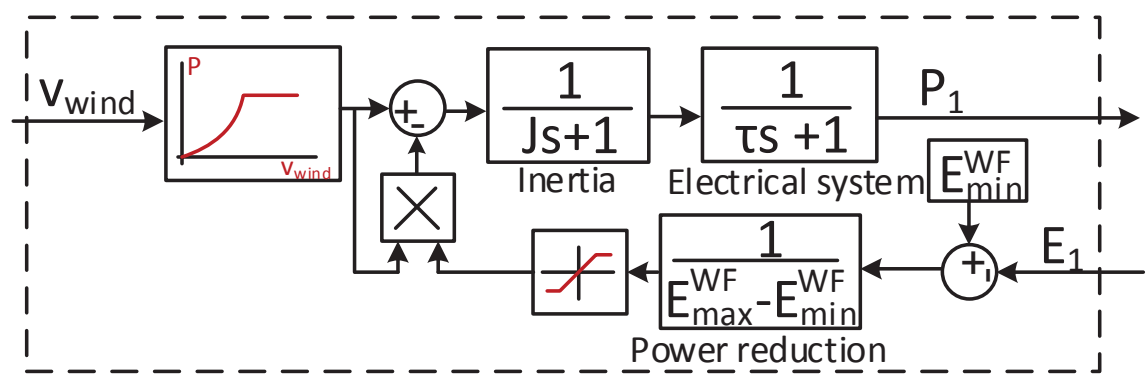

Figure 8: Wind farm simplified model 


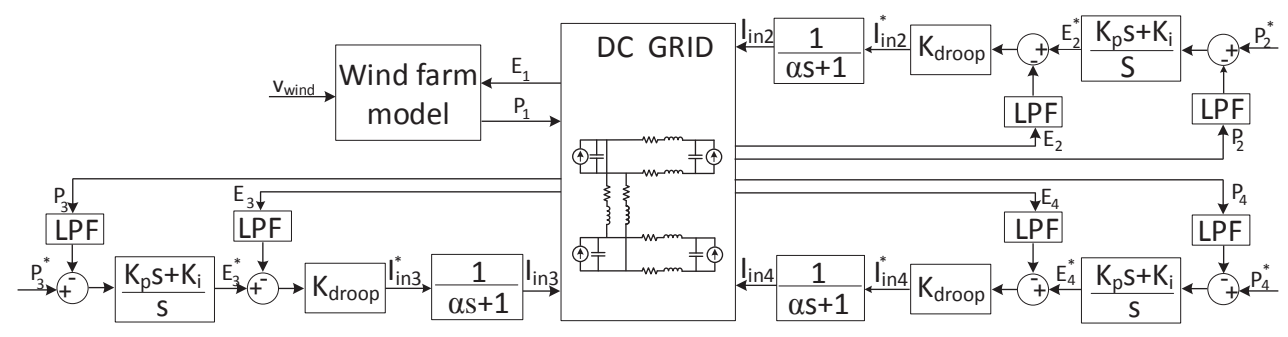

Figure 9: Simplified control scheme

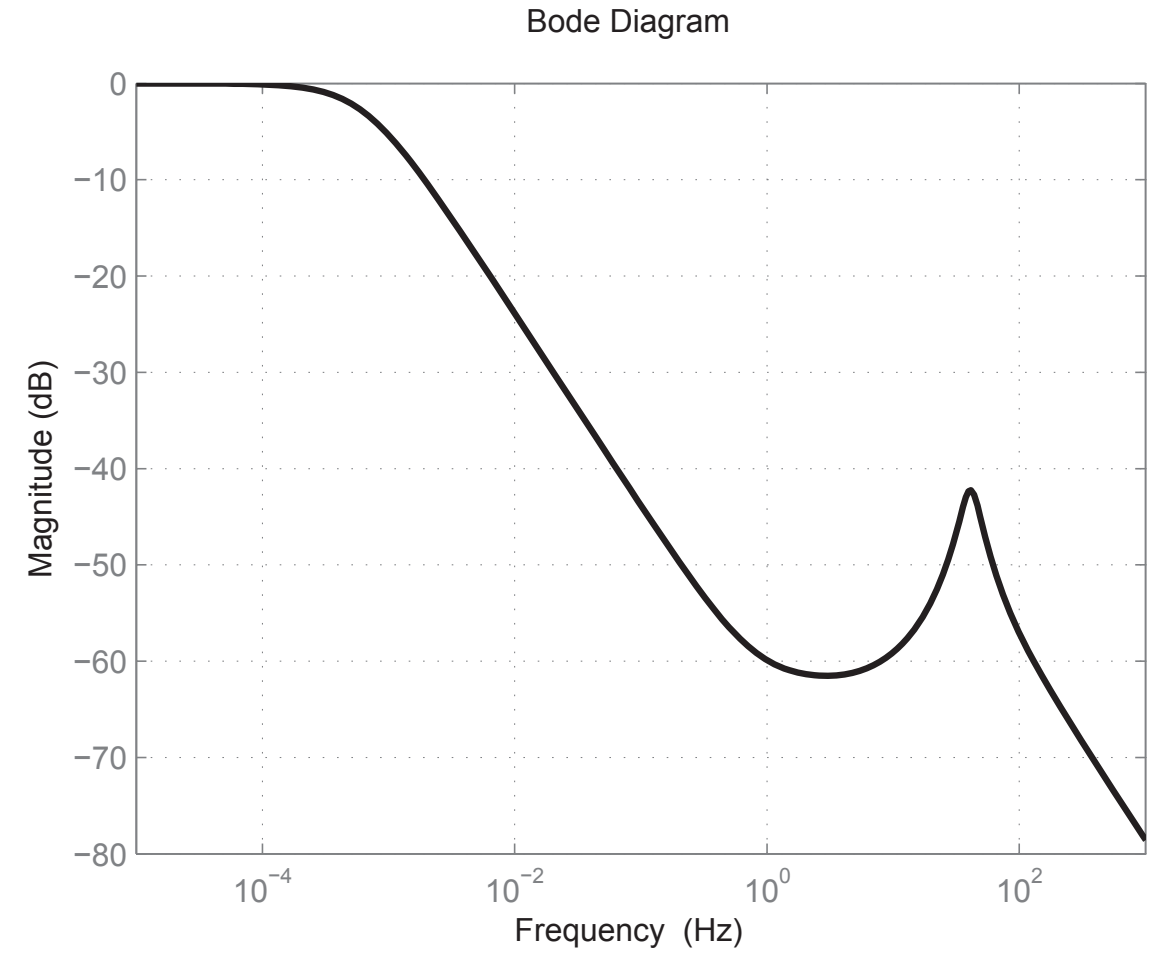

Figure 10: Close loop transfer function of $\frac{P_{x}}{P_{x}^{*}}$ 


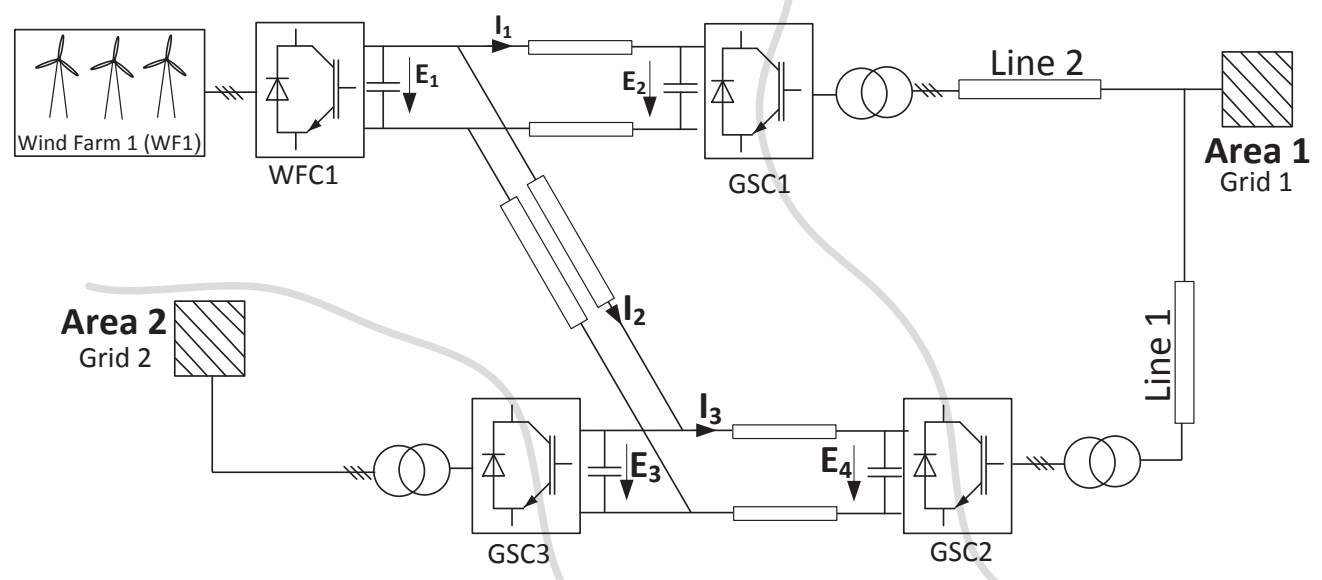

Figure 11: General scheme of the simulated multiterminal system

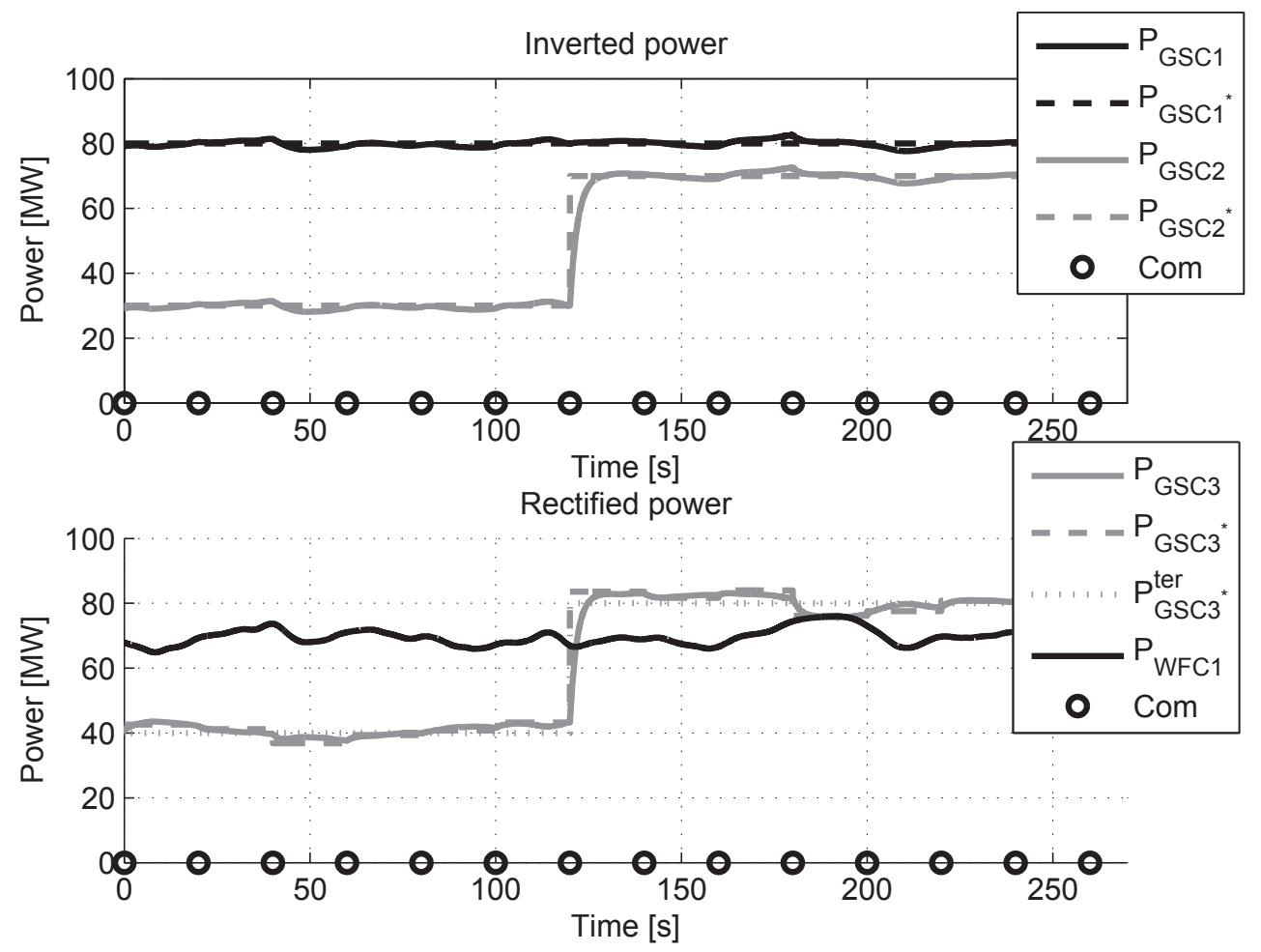

Figure 12: Power evolution during a reference change. 


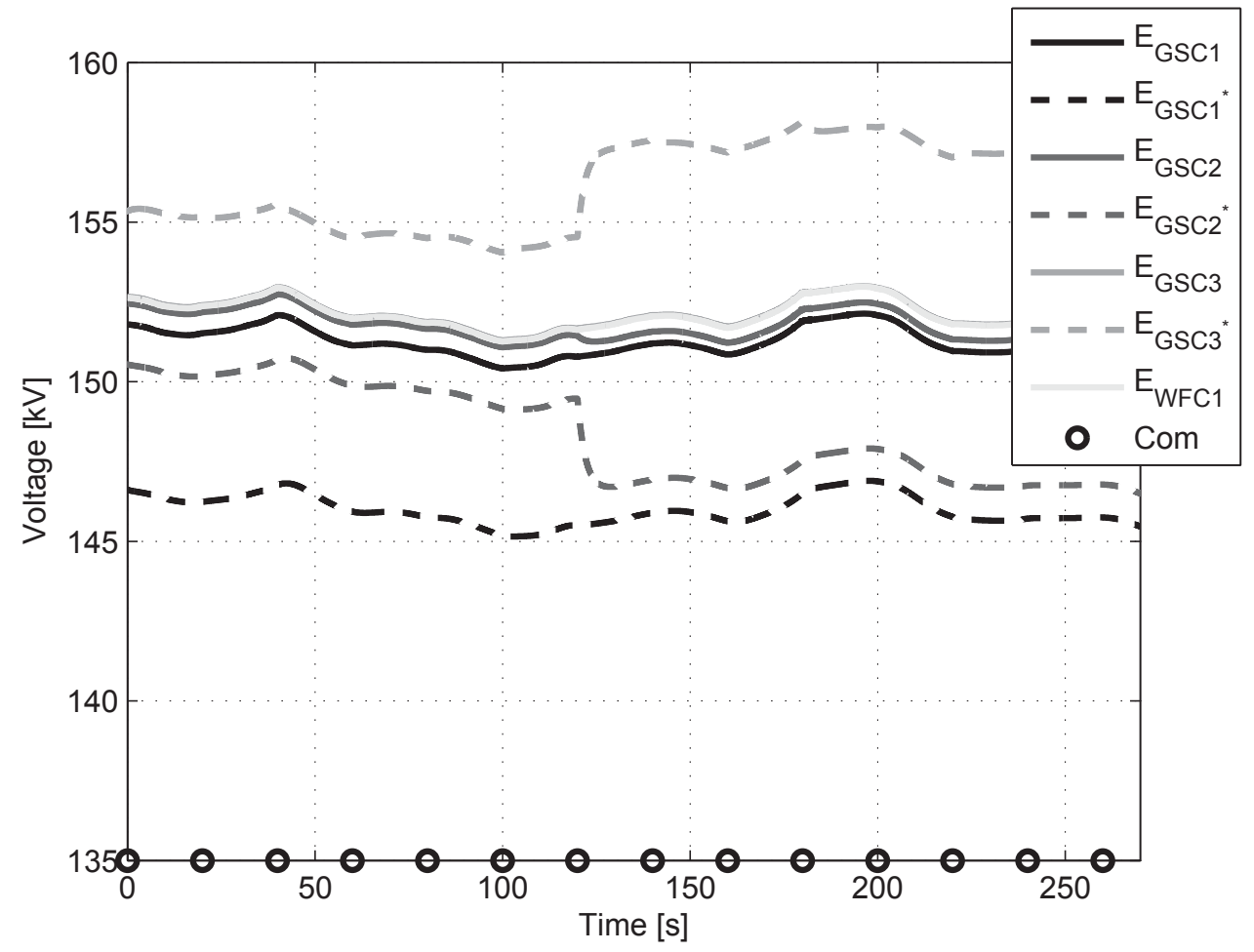

Figure 13: Voltage evolution during a reference change.

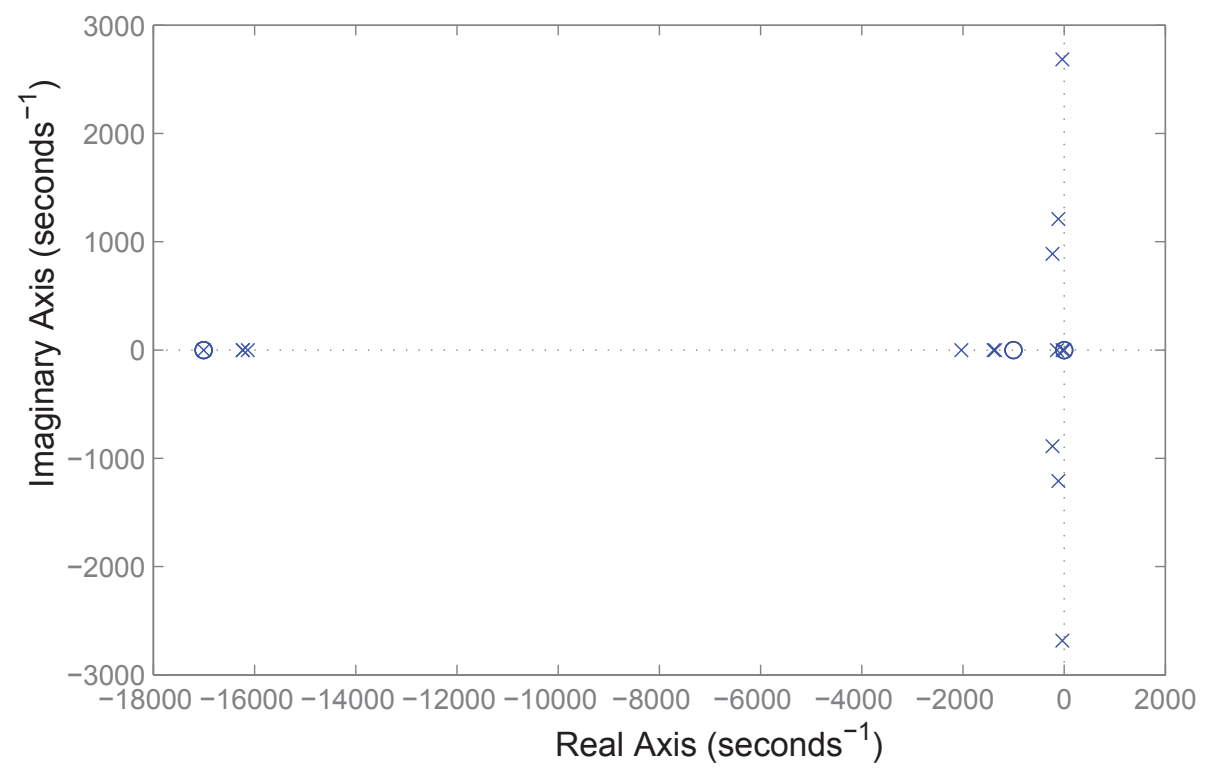

Figure 14: Poles and zeros map for the simulation scenario 1 


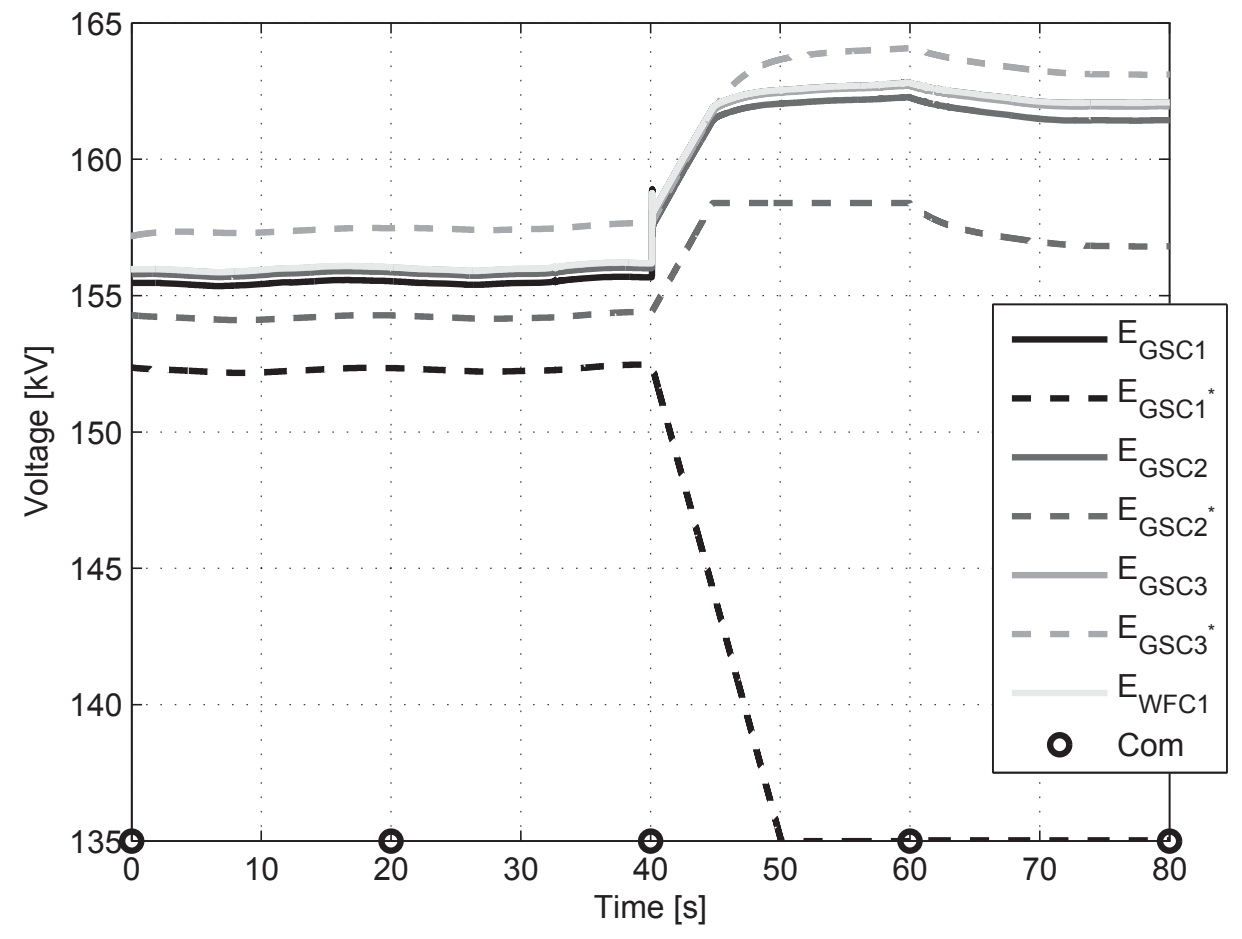

Figure 15: Voltage evolution during a reference change. 


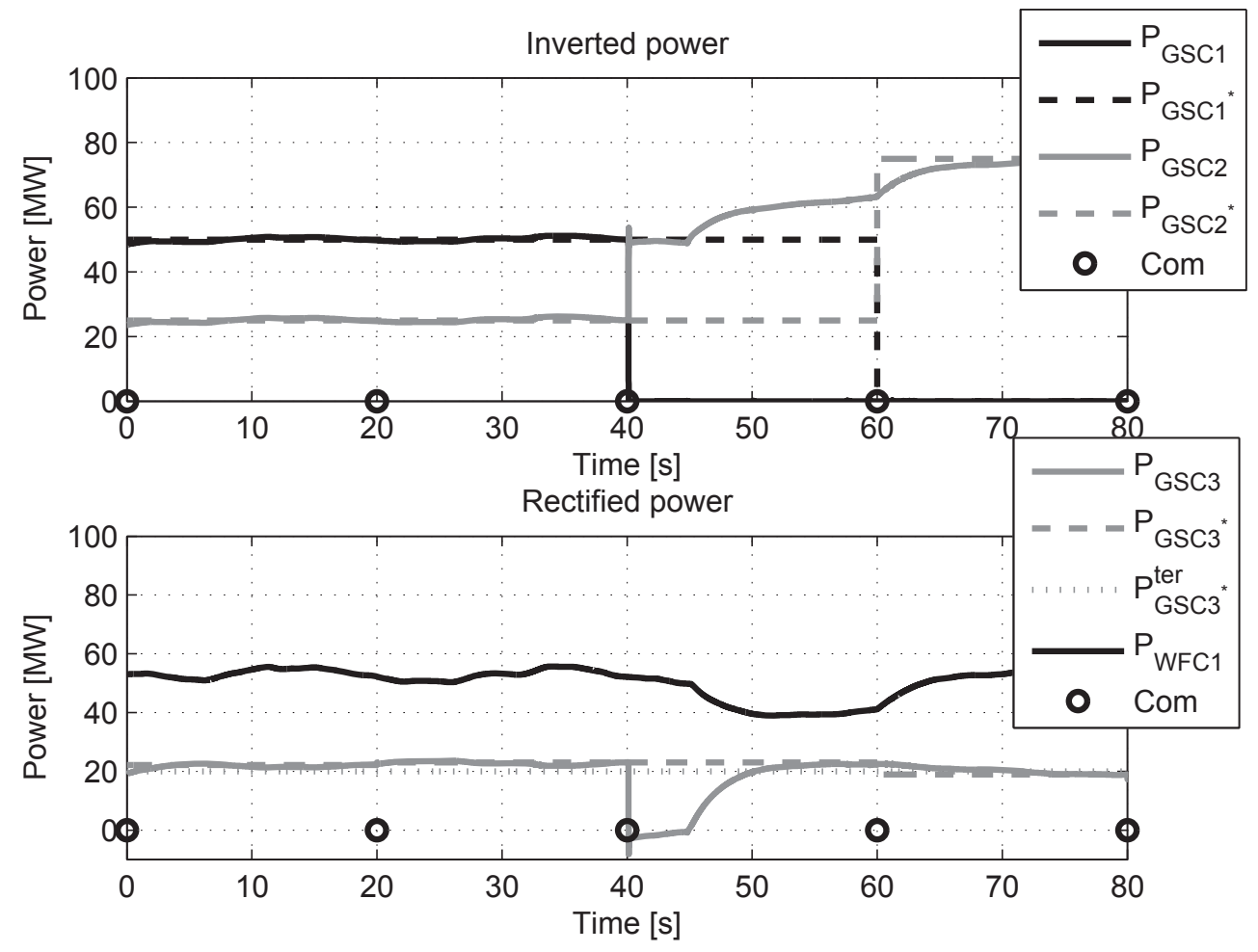

Figure 16: Power evolution during a reference change. 